Brit. J. prev. soc. Med. (1976), 30, 175-179

\title{
Epidemiology of twin births from a climatic point of view
}

\author{
KATSURA KAMIMURA
}

Department of Hygiene and Preventive Medicine, Niigata University School of Medicine, Niigata, Japan

\begin{abstract}
Kamimura, K. (1976). British Journal of Preventive and Social Medicine, 30, 175-179. Epidemiology of twin births from a climatic point of view. The twinning rate was analysed using figures taken from statistics for Japan. During the years 1955 to 1959 there were 58570 twin deliveries out of a total of 9088233 , a frequency of 6.44 per 1000 . Using Weinberg's differential method for zygosity estimation, the monozygotic twinning rate was 4.04 per 1000 and the dizygotic was $2 \cdot 40$. Twinning rates in 46 prefectures were also estimated and their correlations with meteorological parameters as well as with the mortality from cerebrovascular disease were examined. The twinning rates increased from a low level in the south west to a high level in the north east of Japan. The tendency was more obvious for the dizygotic than the monozygotic twinning rate. A negative correlation was observed between incidence rates of dizygotic twins and mean airtemperatures throughout the year, and a positive one between incidences of dizygotic twins and mortality rates for vascular lesions affecting the central nervous system in 46 prefectures. A seasonal variation of twinning rates was also observed in Niigata City for statistics of births during the periods 1948-55 and 1963-70. This took the form of a bimodal curve, with high conception rates for twin births in intermediate mild seasons, the spring and autumn and, low rates in the more stressful hot and cold seasons. These relationships between climate and twin births within a single race-group are discussed.
\end{abstract}

There is a well recognized ethnic difference in the twinning rate, twin births being common in the Negro, less frequent in the Mongolian, and intermediate between these two in the Caucasian. It is widely accepted that the frequency of monozygotic twins is roughly uniform throughout the world, but that of dizygotic twins varies considerably between races. However, there is little difference in the dizygotic twinning rate within each race (Gedda, 1961; Bulmer, 1970), and therefore, the difference between ethnic groups in their twinning rate seems to be of genetic origin.

Apart from the ethnic view, the literature is scant on the regional characteristics of the twinning rate. Davenport (1930) reported a high twinning rate in northern and a low rate in tropical countries. Bulmer (1960) observed that there was an increase in the twinning rate from a low level in the south west to a high level in the north east in France, due to differences in the dizygotic rather than the monozygotic twinning rates. The reports suggest that environmental factors may have an effect on the twinning rate. National populations are often ethnically heterogeneous, particularly in Europe, so that it would be difficult to study environmental influences on the twinning rate without paying regard to the ethnic factor.

However, a study of environmental factors which may have an effect on twin births is practicable in Japan. The main reasons for this are that:

1. The Japanese are ethnically homogeneous; there has been little racial mixture in the history of Japan, at least for the past 20 centuries.

2. A considerable difference in climate exists among the 46 prefectures because the long and narrow chain of Japanese islands stretches from the south west to the north east over the whole temperate zone.

3. Records of the Japanese census are considered to be reliable. 
If, in a single ethnic-group, the regional difference in twin births is related to the climate, a seasonal variability of twin births may also be observed.

The present paper deals with the climatic effect upon the twin births by analysing a geographical distribution as well as a seasonal fluctuation of the twinning rates in Japan.

\section{Materials AND Methods}

In order to analyse the regional variability of twinning rates, data were taken from the Bulletins of Vital Statistics issued annually by the Ministry of Health and Welfare of Japan. Geographical division was made according to the prefectures which are administratively autonomous units. Registration of multiple births, whether live or stillborn,* was made law in 1948 , and its reliability since then has much improved.

Statistics on twin births were given in the Japanese Vital Statistics for the first time in 1951. Figures for both twin births and the zygosity estimation for each prefecture were available only from 1955 to 1959. During this period, the movement of working population from rural to urban areas was not so remarkable as in subsequent years.

The zygosity of twins was estimated using Weinberg's differential method (Weinberg, 1901). No correction of the zygosity rate by sex ratio was made because this would have had little effect on the results.

The twinning rate for each prefecture was standardized for maternal age by the indirect method, using age-specific twinning rates and the maternal age distributions (Bulmer, 1960) which were obtained from birth statistics for the years 1960-67.

*The Japanese Vital Statistics define the word 'stillbirth' as a delivery of the dead fetus after the thirteenth week of gestation.
Meteorological data for each prefecture were represented by those for its capital given in the $z$ official handbook published by the Meteorological $\stackrel{\curvearrowright}{\curvearrowright}$ Agency of Japan. Mortality data for vascular lesions affecting the central nervous system were taken from the report of Segi (1970).

Data on twin births for the analysis of the seasonal 들 fluctuation were taken from the birth statistics of $\frac{\bar{c}}{\bar{c}}$ Niigata City. Niigata City is almost at sea level $\stackrel{\varnothing}{\complement}$ $\left(37^{\circ} 55^{\prime} \mathrm{N}, 139^{\circ} 03^{\prime} \mathrm{E}\right)$ and averages of the mean dry-bulb temperature vary from $2^{\circ}$ to $26^{\circ} \mathrm{C}$. throughout the year, and the four seasons alternate? in a regular manner.

Figures on the twin births for the periods ${ }^{\omega}$ 1948-55 and 1963-70 were available but, unfor- $\bar{\Phi}$ tunately, those for the years between 1956 and 1962? were not complete, so this period was omitted from the analysis.

As there was little difference between the $\vec{V}$ seasonal patterns of twin births during 1948-55 $\mathrm{G}$ and 1963-70, the combined figures for both periods 5 were used in calculating the twinning rate for eaen $\vec{C}$ month.

\section{RESULTS}

Annual incidences of twin births during years 1955 and 1959 are shown in Table I. Thepe were 58570 twin births out of a total of 908823 the frequency being $6 \cdot 44$ per 1000 .

Weinberg's assumption gave the monozygottco twinning rate as 4.04 and the dizygotic 2.40 per 1000.

The annual trend of twinning rates showed noo appreciable change. With the one way analysis of variance of twinning rates by year and prefecture, $\overrightarrow{0}$ the variation between prefectures was much greater 3 than that within years, and the difference was? highly significant $(P<0.01)$.

Standardized monozygotic and dizygotic twinning rates for 46 prefectures during the period 1955-59? are shown in Figs 1 and 2. The coefficient of

TABLE I

FREQUENCIES OF TWIN DELIVERIES IN JAPAN, 1955-59

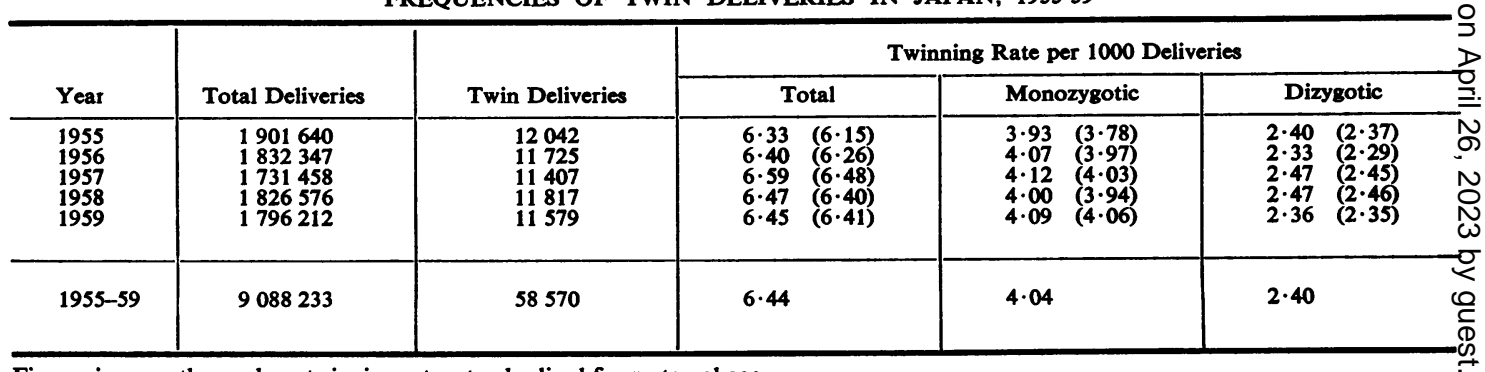

Figures in parentheses show twinning rates standardized for maternal age. 


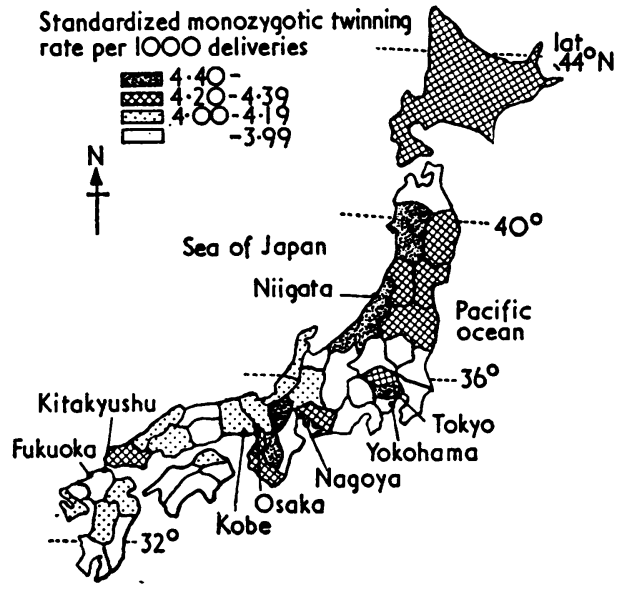

Fro. 1. Distribution of standardized monozygotic twinning rates in Japan, 1955-59.

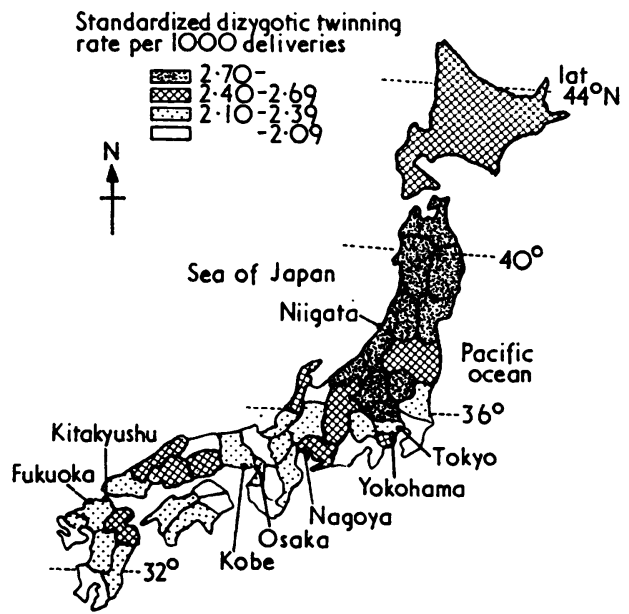

Fig. 2. Distribution of standardized dizygotic twinning rates in Japan, 1955-59.

variation of the monozygotic twinning rates in 46 prefectures during the period of $1955-59$ was $10.9 \%$ which was smaller than that of the dizygotic rates, $17 \cdot 6 \%$.

Correlations between monozygotic and dizygotic twinning rates in 46 prefectures together with latitude, climatic parameters, and mortalities from cerebrovascular disease are shown in Table II, with the probability level of significance.

Table III gives numbers of total and twin deliveries, relative ratios of twin deliveries, and 'unsmoothed' and 'smoothed' twinning rates by month in Niigata City for the periods 1948-55 and 1963-70.

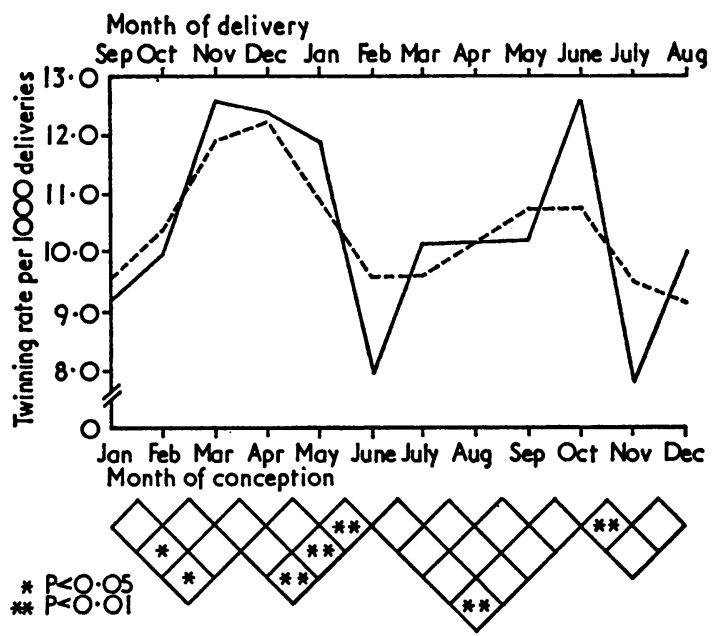

Fio. 3. Seasonal variation of the twinning rates in Niigata City. Dotted line indicates twinning rate using formula $b^{\prime}=a+2 b+c$

4

In Fig. 3, the solid line represents the seasonal variation of 'unsmoothed' twinning rates. Differences among twinning rates in representative months of four seasons were analysed by the $\chi^{2}$ test, and at the bottom of the figure are shown significant changes with levels of probability. There is a bimodal curve throughout the year rising in intermediate mild seasons (spring and autumn) and falling in severe seasons (cold winter as well as hot summer). The dotted line shows the seasonal variation of 'smoothed' twinning rates, which has a more obvious seasonal fluctuation.

\section{Discussion}

Some doubts about Weinberg's differential method for estimating the zygosity of twins were raised by findings of placental morphology and genetic characteristics, such as blood type or fingerprint (James, 1971; Myrianthopoulos, 1970; Renkonen, 1967). The main criticism was that the proportion of dizygotic twins was underestimated in Weinberg's assumption, but it is not practicable to attempt a precise diagnosis of zygosity at the time of delivery on a population scale. It is also said that the discrepancy between the proportion of monozygotic to dizygotic twins diagnosed by the precise method and that estimated by Weinberg is small (Cameron, 1968; Potter, 1963). Weinberg's assumption can, therefore, still be useful for zygosity estimation in a large sample of twins (Bulmer, 1970; Myrianthopoulos, 1970). 
TABLE II

CORRELATION-COEFFICIENTS BETWEEN MONOZYGOTIC OR DIZYGOTIC TWINNING RATE IN 46 PREFECTURES AND THEIR METEOROLOGICAL PARAMETERS OR MORTALITIES FROM CEREBROVASCULAR DISEASE

\begin{tabular}{|c|c|c|}
\hline Variable & Monozygotic & Dizygotic \\
\hline Latitude & $0.371 \dagger$ & $0.573 \ddagger$ \\
\hline $\begin{array}{l}\text { Annual temperature }(1941-70) \\
\text { Mean } \\
\text { Highest } \\
\text { Lowest } \\
\text { Total annual duration of sunshine }(1941-70) \\
\text { Mean humidity }(1941-70)\end{array}$ & $\begin{array}{l}-0.309 * \\
-0.364 \dagger \\
-0.214 \\
-0.288 \\
-0.223\end{array}$ & $\begin{aligned}-0.619 \ddagger \\
-0.583 \ddagger \\
-0.630 \ddagger \\
-0.200 \\
0.063\end{aligned}$ \\
\hline $\begin{array}{l}\text { Age-adjusted mortality rate for vascular lesions affecting the } \\
\text { central nervous system (1958-62) } \\
\text { Male } \\
\text { Female }\end{array}$ & $\begin{array}{l}0 \cdot 195 \\
0 \cdot 194\end{array}$ & $\begin{array}{l}0.672 \ddagger \\
0.706 \ddagger\end{array}$ \\
\hline$* P<0.05 \quad+P<0.02 \quad \ddagger P<0.001$ & & \\
\hline
\end{tabular}

NUMBERS OF TOTAL AND TWIN DELIVERIES, RELATIVE RATIOS OF TWIN DELIVERIES, AND TWINNING RATES음

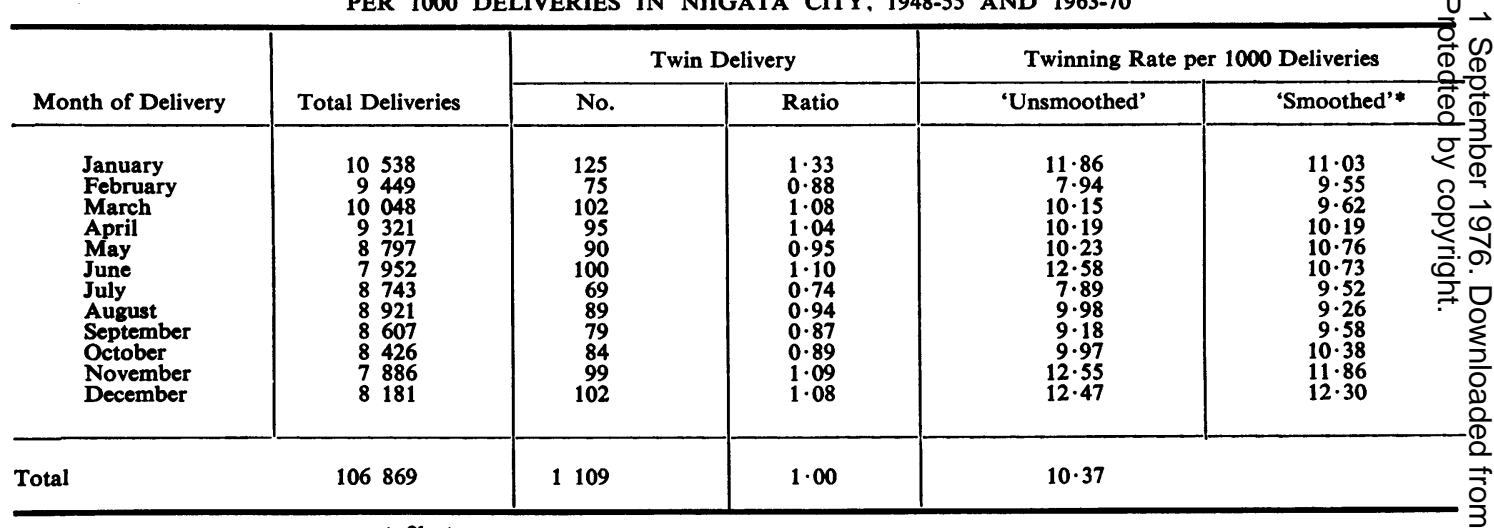

"Smoothed' by the formula $b^{\prime}=\frac{a+2 b+c}{4}$, where $b$ is the twinning rate of a certain month, and $a$ and $c$ are the twinning rates of its preceding and succeeding months.

In the present study the total, monozygotic, and dizygotic twinning rates during $1955-59$ were $6 \cdot 44$, $4 \cdot 04$, and $2 \cdot 40$ respectively per 1000 deliveries. The figures were similar to those reported previously in Japan and for foreign populations of oriental origin (Komai and Fukuoka, 1936; Kang, 1962; Ping and Chin, 1967; Shipley et al., 1967).

As Fig. 2 shows, the standardized dizygotic twinning rate was higher in the north east than in the south west prefectures. This trend was in close agreement with Bulmer's survey in France (Bulmer, $1960,1970)$. A similar trend was also observed in the monozygotic twinning rate, but less marked. It is therefore considered that the regional variation in the twinning rates was mainly due to the difference in dizygotic twinning rates.
In Japan, urbanization has mainly developed in? the cities along the Pacific Ocean (Tokyo, Nagoya, $\frac{}{3}$ Osaka, etc.), but, as a rule, both north east and. south west areas of the country have escaped.o It does not appear from Figs 1 and 2, that there was a clear relationship between the twinning rate and음 the progress of urbanization.

As shown in Table II, there were significant? correlations between the twinning rate and latitude, $N$ and negative correlations between the dizygotic twin incidence and the mean, highest, or lowest 0 air temperatures. It may therefore be suggested that the regional difference in dizygotic twin births్ is influenced by the difference in climatic conditionse Interestingly enough, there was also a strong correla tion between the dizygotic twinning rate and the 
age-adjusted mortality rate for vascular lesions affecting the central nervous system in the 46 prefectures. It is well known that deaths from cerebral apoplexy are greatly influenced by the climate in Japan.

The birth rate is affected not only by the reproductive capacity in man but also by social factors and customs which include family planning, the popular season for marriages, etc. These influences accordingly make it difficult to interpret the effect of season on human reproductivity, but on the other hand, the rate of twin births is free from such complicating factors.

There was a definite bimodal curve of the monthly conception rates for twin births in Niigata City, high in intermediate mild seasons, spring and autumn, and low in stressful seasons, both hot and cold climates. The curve shows close agreement with that of the level of the gonadotrophic hormone (Watanabe and Yoshida, 1956, 1966), and it is suggested that the pituitary gonadotrophic hormone has an effect on ovulation (Bulmer, 1970; Dean and Keane, 1972).

Little has been written on the effect of seasonal change in twin births (Edwards, 1938; Timonen and Carpen, 1968; Selvin and Janerich, 1972). Although there is a slight shift in the month, the seasonal change for the twinning rates in the present study is essentially the same as that of Edwards (1938) and Timonen and Carpen (1968).

Das (1934) found a variation in twin incidence rates among races, but denied a climatic influence upon the frequency of twins. Gedda (1961) maintained that the latitude and the climate played a secondary role to ethnic factors. Cox (1963) reported in his study in Nigeria that there was an association between a hot, humid climate and the high multiple birth rate. It is likely that an ethnic factor acts more strongly upon the twin incidence rate than any other factor. In order to observe climatic effects upon the twinning rate, it is necessary to minimize ethnic factors as far as possible.

The author expresses his appreciation to $\mathrm{Dr}$ G. Watanabe for his advice.

Requests for reprints: Dr K. Kamimura. Department of Hygiene and Preventive Medicine. Niigata University School of Medicine, Niigata City, Japan.

\section{REFERENCES}

Bulmer, M. G. (1960). The twinning rate in Europe and Africa. Ann. hum. Genet., 24, 121.

(1970). The Biology of Twinning in Man. Clarendon Press, Oxford.
Cameron, A. H. (1968). The Birmingham twin survey. Proc. roy. Soc. Med., 61, 229.

Cox, M. L. (1963). Incidence and aetiology of multiple births in Nigeria. J. Obstet. Gynaec. Brit. Cwlth, 70, 878.

DAS. K. (1934). Twin pregnancy (a demographic and ethnic study). J. Obstet. Gynaec. Brit. Emp., 41, 227.

DAVENPORT, C. B. (1930). Littersize and latitude. Arch. Rass. ges. Biol., 24, 97.

DeAN, G. and Keane, T. (1972). An investigation of the high twinning rate in the Republic of Ireland. Brit. J. prev. soc. Med., 26, 186.

EDWARDS, J. (1938). Season and rate of conception. Nature (Lond.), 142, 357.

GeDDA, L. (1961). Twins in History and Science. Thomas, Springfield, Illinois.

JAMES, W. H. (1971). Excess of like sexed pairs of dizygotic twins. Nature (Lond.), 232, 277.

KANG, Y. S. (1962). On twin-births in Korean population. Jap. J. hum. Genet., 7, 30.

KomaI, T. and FukuOKA, G. (1936). Frequency of multiple births among the Japanese and related peoples. Amer. J. phys. Anthrop., 21, 433.

Myrianthopoulos, N. C. (1970). An epidemiologic survey of twins in a large, prospectively studied population. Amer. J. hum. Genet., 22, 611.

PING, Y. W. and Chin, C. L. (1967). Incidence of twin births among the Chinese in Taiwan. Amer. J. Obstet. Gynec., 98, 881.

POTTER, E. L. (1963). Twin zygosity and placental form in relation to the outcome of pregnancy. Amer. $J$. Obstet. Gynec., 87, 566.

Renkonen, K. O. (1967). Is Weinberg's differential rule defective? Ann. hum. Genet., 30, 277.

SEGI, M. (1970). Mortality by causes of death and prefectures in Japan (1953-1967). Department of Public Health, Tohoku University School of Medicine, Sendai, Japan. (In Japanese).

Selvin, S. and JANERICH, D. T. (1972). Seasonal variation in twin births. Nature (Lond.), 237, 289.

Shipley, P. W., Wray, J. A., Hechter, H. H., Arellano, M. G., and BORHANI, N. O. (1967). Frequency of twinning in California. Its relationship to maternal age, parity and race. Amer. J. Epidem., 85, 147.

Timonen, S. and CARPEN, E. (1968). Multiple pregnancies and photoperiodicity. Ann. Chir. Gynaec. Fenn., 57, 135.

Watanabe, G. and Yoshida, S. (1956). Climatic effect on urinary output of neutral 17-ketosteroids. J. appl. Physiol., 9, 456.

— and - (1966). Seasonal effects upon column chromatographic fractions of urinary 17-ketosteroids. Clin. Endocr., 14, 333. (In Japanese).

WeINBERG, W. (1901). Beiträge zur Physiologie und Pathologie der Mehrlingsgeburten beim Menschen. Pflügers Arch. ges. Physiol., 88, 346. 